\title{
Italians' use of time during the economic crisis: implications for the gender division of labour
}

\author{
Marina Zannella ${ }^{1, *}$ and Alessandra De Rose ${ }^{1}$
}

\section{Abstract}

This article builds on time use micro-data for Italy to analyse the evolution of individuals' time allocation during the 2002-2014 period, with a gender-specific focus. We are particularly interested in comparing changes that occurred between the years prior to and after the onset of the recent economic crisis. We use regression analysis to measure differences between years in the average use of time of men and women for personal care, education, paid work, unpaid work, and leisure over the considered period(s). In order to gain more insight into gender differences in time use behaviours, we further break down unpaid work and free time into detailed activities. We document a decrease of about two hours per week in female housework coupled with a similar increase in male unpaid work over the entire period. However, while signs of this gender convergence were already evident for women in the years before the recession, we do not find any significant change in male unpaid work between 2002 and 2008. It was only after the onset of the economic crisis, and the consequent losses in paid work hours, that men started spending more time on housework and family care.

\section{Introduction}

How did individuals allocate their forgone hours of market work during the recent economic recession? Was the Great Recession a "Great Vacation"? These are among the questions posed by Aguiar et al. (2014) in their study on Americans' use of time during the recent economic crisis. Results, based on data from the American Time Use Survey for the 2003-2010 period, showed that leisure absorbed more than $50 \%$ of the foregone market work hours, with sleeping and television

\footnotetext{
${ }^{1}$ Department of Methods and Models for Economics, Territory and Finance, Sapienza University of Rome, via del Castro Laurenziano n.9, 00161 Rome, Italy

*Correspondence to: Marina Zannella, marina.zannella@uniroma1.it
} 
watching accounting for most of the increase in the amount of time spent on leisure. About $30 \%$ of the foregone market work hours were reallocated to housework, and about 5\% were reallocated to child care. The remaining time was absorbed by increasing investments in education, health care, and civic activities (about 12\%); whereas a smaller, but still significant, fraction of the foregone working hours were devoted to job search activities (between 2\% and 6\%). By contrast, Lahart and Zhao (2010) found support for the "Great Vacation" narrative, as they reported evidence for the United States that the unemployed were frittering away their time by devoting $80 \%$ of their forgone market work hours to leisure, while barely increasing the amount of time they spent on unpaid work. Folbre (2011) stressed the role of household production as a market substitute for consumer expenditures, noting that in times of economic hardship, individuals can save money by, for example, spending their time preparing meals instead of going to restaurants, cleaning the house instead of hiring a maid, or doing home repairs rather than paying a professional. Individuals can also save money by obtaining help from family members: e.g. grandparents, uncles, and aunts can care for children instead of a paid baby-sitter. In addition, parents can exchange favours, such as driving children to school.

A large body of literature has demonstrated that the effects of the recent and past economic crises differed by gender (for the effects of past crises, see, for example, Rubery 1988). The term "mancession" has been coined to describe the greater employment losses among men than among women during the recent recession (Sierminska and Takhtamanova 2011). According to Karamessini and Rubery (2014), the gendered dimension of the European recession changed over time, moving from being a "he-cession" to a "she-austerity". In other words, as the initial stages of the crisis mainly hit the manufacturing and construction economic sectors, more men than women lost their jobs, and the gender gap narrowed through the deterioration of the position of men. Yet because the later stages of the crises were dominated by austerity policies, the recession ultimately had a more negative impact on the demand for female labour and on social policies - which, in turn, had negative implications for gender equality. However, according to Périvier (2014), the mancession was particularly acute in Mediterranean countries (including Italy), where, unlike in other European countries, women experienced more favourable employment conditions than men throughout the crisis.

Most existing studies on this topic have analysed the implications of the economic crisis for gender equality from a labour market perspective, whereas only a limited number of studies have examined the impact of the economic crisis on time use among men and women. For example, Aguiar et al. (2014) documented that American men and women responded similarly to market work reductions during the economic downturn, with the exceptions that women were more likely to reallocate time to home production and sleep, whereas men tended to spend more time on education and TV watching. Hofferth and Goldscheider (2010) argued that the reaction of today's fathers to recessions may differ from those of men 
in the Great Depression, when male unemployment challenged the paternal role. They observed that given the relatively recent changes in attitudes towards gender roles, fathers who spend less time on paid work activities may become increasingly involved in family tasks. At the European level, there has been a lack of research on the effects of the economic crisis on time allocation, primarily due to data limitations. As Time Use Surveys (TUS) are not conducted regularly in many European countries, comparing time allocation patterns over recent years is difficult. Based on time use observations for Italy, Slovenia, Turkey, and Spain, Bettio et al. (2012) have suggested that unpaid work may have increased during the crisis in European countries characterised by very large gender disparities in domestic and care activities, thus slowing down the pre-recession trend towards the narrowing of the gender gap in home production. However, at the time the study was conducted, the most recent time use data available for the four countries were for the years around 2009, which did not allow the authors to evaluate the effects of the recession on the gender division of family work over the longer term.

This article draws on Italian time use micro-data to investigate the evolution of gender-specific patterns in the use of time over three years $(2002 / 3,2008 / 9$, and 2013/4). In particular, we aim to analyse whether and, if so, to what extent the economic crisis has led to reductions in paid work hours, and has thus affected the allocation of time to paid/unpaid work, education, and leisure activities among Italian men and women. The focus on Italy is of considerable interest for several reasons. First, among Western industrialised countries, Italy stands out as having the widest gender gap in household labour (Bloemen et al. 2010; Menniti et al. 2015). Second, Italy is among the European countries that have experienced the most severe consequences of the economic crisis, and, unlike in other European countries, these consequences have been particularly adverse for men during all stages of the recession. Last but not least, as Italy is one of the few European countries where time use surveys are conducted on a regular basis, recent data on time use for the Italian population are available.

The rest of the article is organised as follows. We start with an overview of the Italian context by briefly describing the recent evolution of the country's main male and female employment/unemployment indicators. Then, we outline the data and methods used to measure changes in gender-specific time use behaviours over the considered period. Our main results are presented and discussed in section four. The last section concludes.

\section{Country context: recent labour market dynamics}

Figure 1 shows the evolution of the employment rate in Italy during the period from 1999 to 2017. Before the recession, Italy's labour market situation was favourable, as the country registered an overall increase of six percentage points (p.p.) in the employment rate between 1999 and 2008. Over this period, levels of employment 
Figure 1:

Italy - Employment rate by year and gender

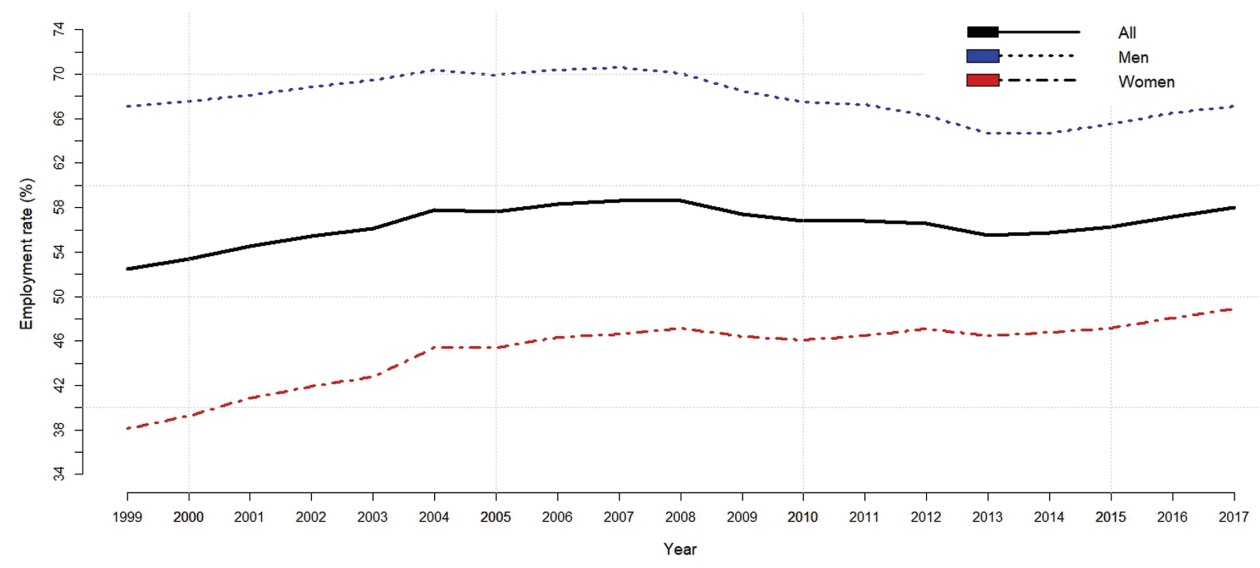

Source: Eurostat, Labour Market Statistics.

rose by three p.p. for men (from $67.1 \%$ to $70.6 \%$ ), while progress for women was even greater, with levels of female employment growing nine p.p. (from $38.1 \%$ to $47.2 \%$ ). However, despite these improvements in the labour market participation of women, Italy was (and continues to be) far from reaching the Lisbon target of $60 \%$ female employment.

Starting in 2008, the employment rate decreased for both men and women, although the decline was greater and more prolonged for men than it was for women. Male employment, which had been fairly stable at the European average of $70 \%$, declined to $64.7 \%$ in 2015 . By contrast, only a slight decrease in the female employment rate was recorded between 2008 and 2010 (46.1\%).

Meanwhile, the female unemployment rate (despite being generally higher) grew less than the male unemployment rate, indicating that women had a relative advantage during the Great Recession (Figure 2). Between 1999 and 2007, the unemployment rate fell from $9 \%$ to $5 \%$ for men and from $16.4 \%$ to $9 \%$ for women. The first signs of the recession were already visible in 2008, when the declining trend started to reverse. Unemployment rose to $6.6 \%$ for men and $9.3 \%$ for women in 2009 , and peaked in 2014 at $11.6 \%$ for men and $13.8 \%$ for women. $^{1}$

\footnotetext{
1 The increase in female labour market participation is partly attributable to the implementation of the 2008 law on the regularisation of illegal workers in the care sector (the great majority of whom were foreign women).
} 
Figure 2:

Italy - Unemployment rate by year and gender

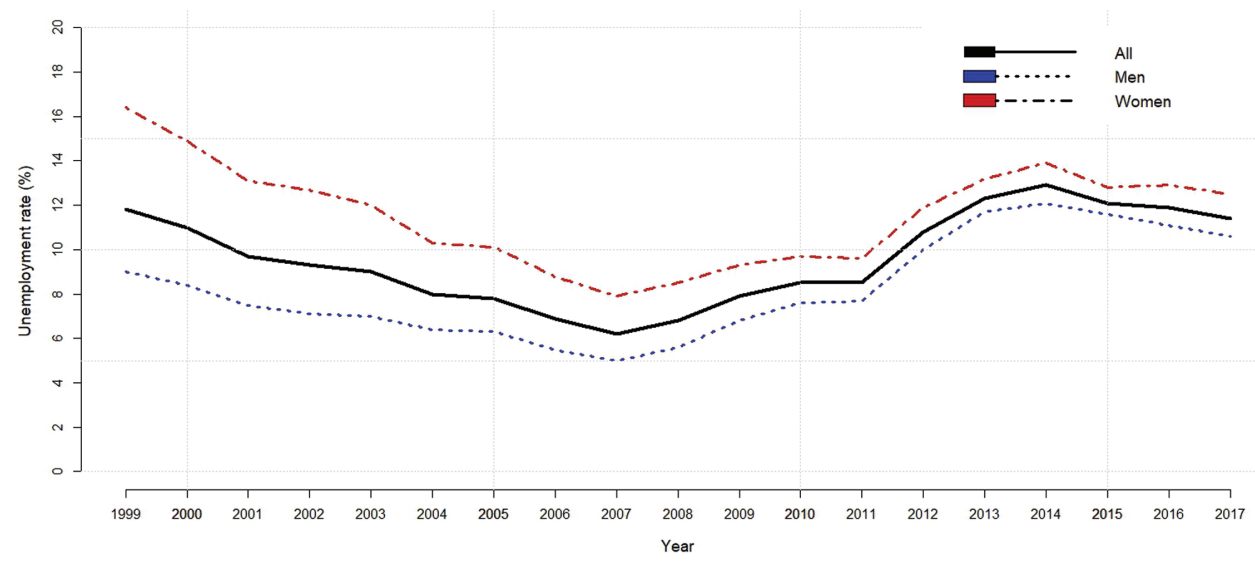

Source: Eurostat, Labour Market Statistics.

The combined effect of decreasing employment and increasing unemployment is also visible in the number of average weekly hours devoted to paid work by the working-age population (Figure 3).

In 1999, men aged 15-64 spent, on average, 28h per week working in the market; compared to $14 \mathrm{~h}$ per week for women of the same ages. ${ }^{2}$ The number of hours worked was fairly stable for men (about 29 hours per week) and women (15 hours per week) in the following years, until 2008, when it started to decline slightly (although it should be noted that, as in the case of the employment and unemployment rates, the effects of the recession were more visible starting in 2009). Between 2007 and 2014, the average number of hours worked dropped by more than $3 \mathrm{~h}$ per week for men, but by less than $1 \mathrm{~h}$ per week for women. The reduction in hours worked at the population level may be attributable not only to the effect of declining employment levels, but to an increase in part-time work. Indeed, in times of economic hardship, a reduction in the working time of employees can be used as an alternative to lay-offs. This observation seems to be confirmed by Eurostat data, which indicate that in Italy, part-time work as a percentage of total employment increased from $4.6 \%$ in 2007 to $8.3 \%$ in 2017 for men, and from $26.8 \%$ to $32.5 \%$ for women. During the same period, the share of total part-time employment in the $15-64$ age group that was involuntary increased by 24.8 p.p. (from $54 \%$ to $78.8 \%$ ) for men and by 21.3 p.p. (from $35.6 \%$ to $56.9 \%$ ) for women.

\footnotetext{
2 According to Eurostat's calculations, the number of hours worked during the reference week includes all hours (including extra hours, either paid or unpaid), but excludes the travel time between home and the place of work, as well as the main meal breaks.
} 
Figure 3:

Italy - Average weekly hours worked by the population aged 15-64 by year and gender

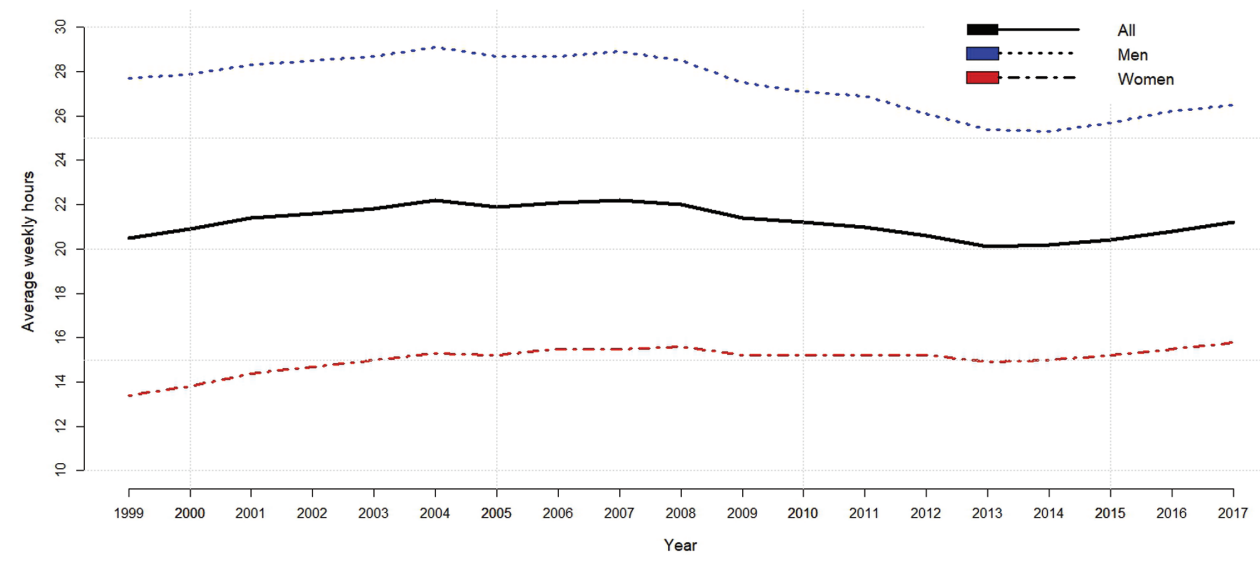

Source: Eurostat, Labour Market Statistics.

To sum up, the gender gap in employment and unemployment narrowed considerably after 2008, as male workers were hit harder than female workers during the economic crisis. A similar pattern could be observed in virtually all European countries, although the gendered impact of the crisis was stronger in Mediterranean countries, such as Greece, Italy, and Spain (Perévier 2014). In these countries, women had an employment advantage relative to men throughout the economic crisis; whereas in most European countries, employment conditions were more favourable for women than for men only during the first stage of the recession (or the "collapse stage"), when there were more job losses in traditionally male economic sectors. Women's employment was sheltered not only by sectoral segregation, but by an "added work effect" (e.g. Eydoux et al. 2014). According to the added worker theory, women's economic behaviour is counter-cyclical: i.e. female labour market participation is likely to increase during recessions, when the main (male) breadwinners experience (or are at risk of experiencing) employment losses; but these women (or the added workers) are likely to exit the labour force again after the economy recovers (e.g. Finegan and Margo 1993).

Based on the statistical information analysed and on the existing literature on the gendered nature of the current economic crisis, we focus in this article on two main research hypotheses. The first hypothesis is that the economic crisis reduced the amount of time men and women spent on paid work, and that this reduction, in turn, affected the time they allocated to other activities. The second hypothesis is that in terms of time use behaviour, Italian men and women responded differently to 
the economic crisis. The next section describes the data and methods used to verify these hypotheses.

\section{Data and methods}

The study builds on micro-data from the Italian Time Use Survey for the years $2002 / 3,2008 / 9$, and 2013/14. More specifically, the surveys were carried out during the following periods: from 1 April 2002 to 31 March 2003, from 1 February 2008 to 31 January 2009, and from 1 November 2013 to 3 October 2014. In both the $2002 / 3$ and the $2008 / 9$ editions of the survey, more than $75 \%$ of the interviews were conducted in the first year (i.e. in 2002 and 2008, respectively); whereas in the 2013/4 edition, most of the interviews were conducted in 2014 (see Table A.1 in the Appendix). We will therefore refer to 2002, 2008, and 2014 as the years of analysis.

We limit our analysis to the population of working ages (between 15 and 64), which provides us with a total sample size of 114,585 individuals $(41,931 / 33,855 / 38,779$ for 2002/2008/2014). The first step in this study was grouping time use activities into meaningful larger categories that are in line with the Harmonised European Time Use Surveys (HETUS, Eurostat 2009) classification, and with the purposes of our analysis. We have identified five main time use categories that are of interest for this study: personal care, education, paid work, ${ }^{3}$ unpaid work, and leisure. In addition, we have identified a sixth residual category for other or unspecified use of time. Given that the great majority of time devoted to personal care (as well as a considerable share of individuals' time) is used for sleeping, we further break down personal care into the sub-categories of sleep and other personal care (including activities such eating, relaxing, washing, and dressing). Similarly, unpaid work is broken down into core family work and care activities: namely, housework, child care, and adult care. We know from previous studies that the gender gap in unpaid work is often reflected in leisure inequality between men and women (i.e. women have less free time than men), and that this phenomenon is particularly relevant for Italy (Zannella et al. 2018). In order to gain more insight into gender differences in the allocation of free time, the leisure category is broken down into civic and religious participation, social life, cultural life, TV, other media, hobbies, and sports. Thus, in total, the time use classification adopted in this study includes six main time use categories and 11 sub-categories. ${ }^{4}$

Our goal is to examine how the time devoted to these time use categories/subcategories changed in the study period, with a gender-specific focus. We

\footnotetext{
3 Paid work refers to time spent working in the individual's main and second jobs, including coffee breaks and travel during/for work.

4 Weighted sample estimates of the average use of time of individuals aged 15-64 years for the considered activities are reported in Table A.2 in the Appendix.
} 
are particularly interested in changes that occurred between the pre-recessionary (2002-2008) and the recessionary (2008-2014) years. However, the shifts in time use patterns may be attributable not only to behavioural changes, but to the structural effects of the composition of the population in each of the three years of analysis. We used a $\chi^{2}$ test to evaluate whether the distribution of the main socio-demographic variables changed significantly between the years. The results of the test show a statistically significant relationship between the distribution of the variables and the survey years (see Table A.3 in the Appendix). Therefore, to measure how the use of time differed over the study period, we regressed the time used by an individual for different time use activities on different years and sociodemographic controls. ${ }^{5}$ Specifically, we used the number of weekly hours devoted to the time use activities under study as dependent variables in our regression analysis. Our explicative variables are year and gender. We are particularly interested in examining the interaction between the period and the time use behaviours of men and women. For this reason, we allow all parameters to differ across years by including an interaction term. The use of time of an individual $i$ is, thus, expressed as follows:

$$
\left\{\begin{array}{l}
T_{k i}=\alpha_{k}+\sum_{j=1}^{3} \beta_{k j} Y_{j i}+\sum_{h=1}^{2} \gamma_{k h} X_{h i}+\sum_{r=1}^{m} \delta_{k r} Z_{r i}+\sum_{j=1}^{3} \sum_{h=1}^{2} \lambda_{k j h} Y_{j i} X_{h i} \\
\quad+\sum_{j=1}^{3} \sum_{r=1}^{m} \varphi_{k j r} Y_{j i} Z_{r i}+\varepsilon_{k i} \\
\sum_{k=1}^{6} T_{k i}=168 \\
i=1,2, \ldots, n
\end{array}\right.
$$

where $n$ is the total sample size, $T_{k i}$ are the weekly hours an individual $i$ devoted to a main time use category $k(k=1,2, \ldots, 6)$ (i.e. to personal care, education, paid work, unpaid work, leisure, and other use of time); $Y_{j}$ is a dummy variable for the year $(j=1,2,3) ; X_{h}$ is a dummy variable for gender $(h=1,2) ; Z_{r}$ are the dummy control variables $(r=1,2, \ldots, m) ; \alpha_{k}$ is the intercept for the time use category $k$; $\beta_{k j}$ is the simple effect of the year $j ; \gamma_{k h}$ is the simple effect of the gender $h ; \delta_{k r}$ is the simple effect of the control variable $r ; \lambda_{k j h}$ is the interactive effect of the year $j$ with the gender $h ; \varphi_{k j r}$ is the interactive effect of the year $j$ with the control variable $r$.

\footnotetext{
5 We include the following demographic controls in the model: the geographical area of residence; the age group; the educational level; marital status; the presence of a child.
} 
Similarly, the weekly hours devoted by an individual $i$ to a sub-category $s$ of the time use activity $k$ is estimated as follows:

$$
\left\{\begin{aligned}
T_{k s i}= & \alpha_{k s}+\sum_{j=1}^{3} \beta_{k s j} Y_{j i}+\sum_{h=1}^{2} \gamma_{k s h} X_{h i}+\sum_{r=1}^{m} \delta_{k s r} Z_{r i}+\sum_{j=1}^{3} \sum_{h=1}^{2} \lambda_{k s j h} Y_{j i} X_{h i} \\
& +\sum_{j=1}^{3} \sum_{r=1}^{m} \varphi_{k s j r} Y_{j i} Z_{r i}+\varepsilon_{k s i} \\
\sum_{s=1}^{S_{k}} T_{k s i}= & T_{k i}
\end{aligned}\right.
$$

where $S_{k}=2$ (sleep, personal care other than sleep) for $k=$ personal care; $S_{k}=3$ (housework, child care, adult care) for $k=$ unpaid work; $S_{k}=6$ (civic and religious participation, social life, cultural life, TV, other media, hobbies, and sports) for $k=$ leisure.

\section{The multivariate results}

Regression estimates of the differences between years in the average use of time for detailed activities are shown Table 1 (both genders), Table 2 (men), and Table 3 (women). ${ }^{6}$ For the population aged 15-64, the amount of time spent on paid work grew substantially in Italy during the pre-recessionary period, increasing by 1.21 hours per week between 2002 and 2008 (equal to $1 \mathrm{~h} 13$ min per week). The largest gains were made by women (+1h $30 \mathrm{~min})$; while the amount of time men spent on market work increased slightly, but the change was not statistically significantly. Men and women spent their free time in similar ways. The amount of time spent on personal care other than sleeping decreased by about $1 \mathrm{~h}$ per week for both genders. In total, the amount of time spent on leisure did not undergo a statistically significant change due to the combination of two different trends. On the one hand, our estimates show a large increase of more than two hours per week spent by both men and women on sports and hobbies, as well as on TV watching. These results are in line with the literature documenting that the time devoted to watching television has increased significantly in recent decades. For example, Gimenez-Nadal and Sevilla (2012) found an almost universal increase in the time spent watching television from the 1970s to the beginning of the 2000s in seven industrialised countries (Australia, Canada, Finland, France, the Netherlands, Norway, and the UK). On the other hand, we observe an overall reduction of more than two hours in the time

\footnotetext{
6 Additional results of the regression analysis on the average use of time by period are reported in
} Tables A.4-A.6 in the Appendix. 


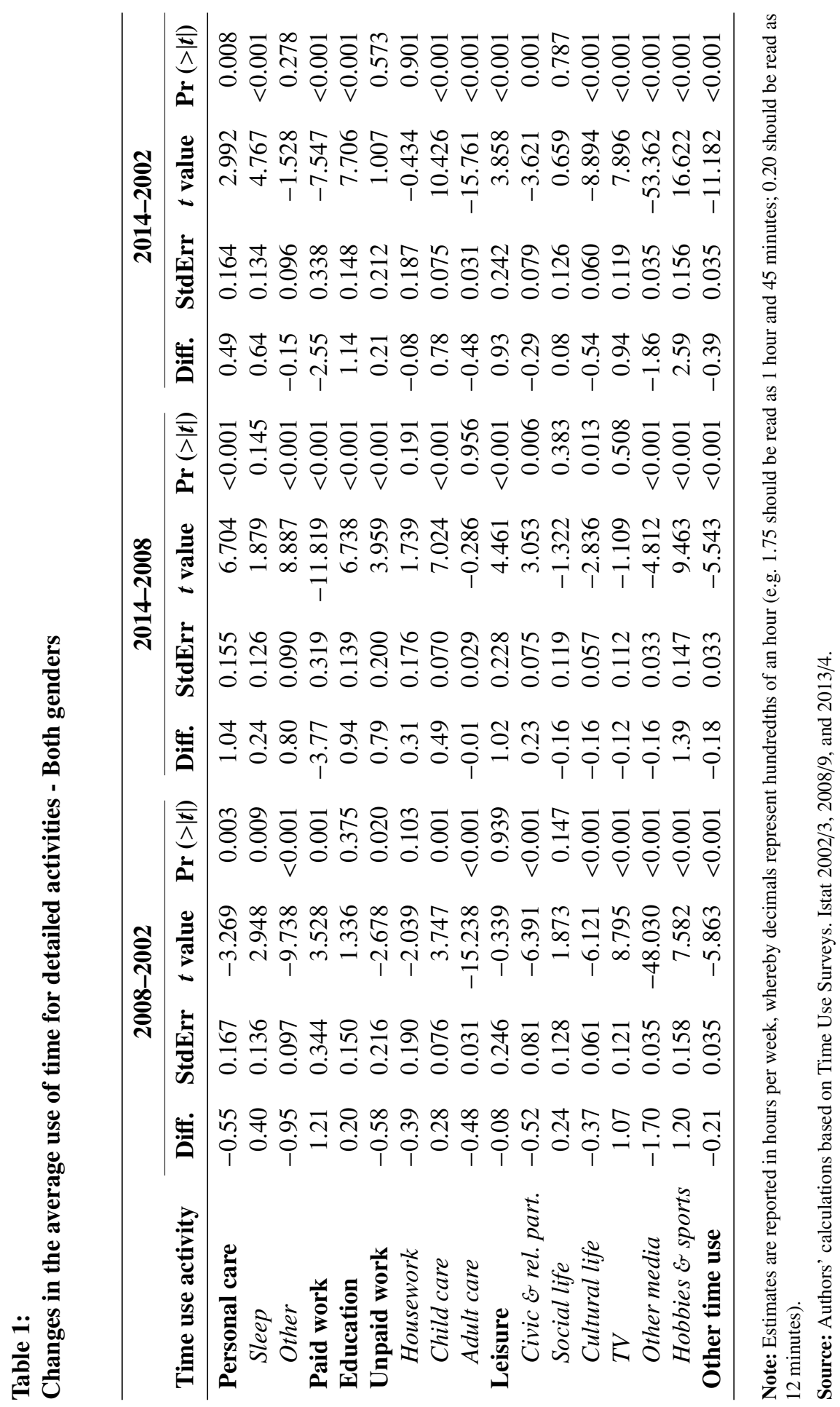




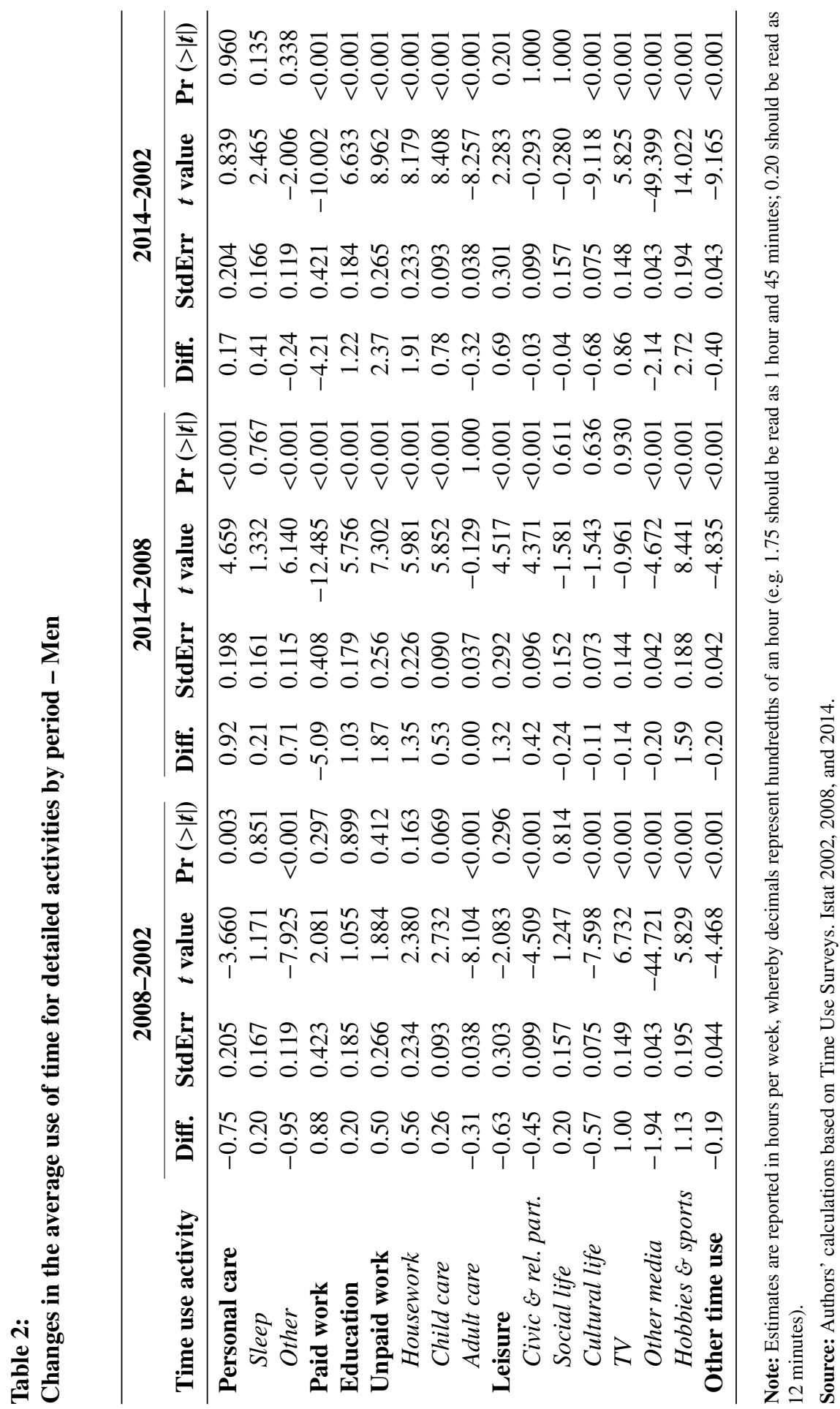



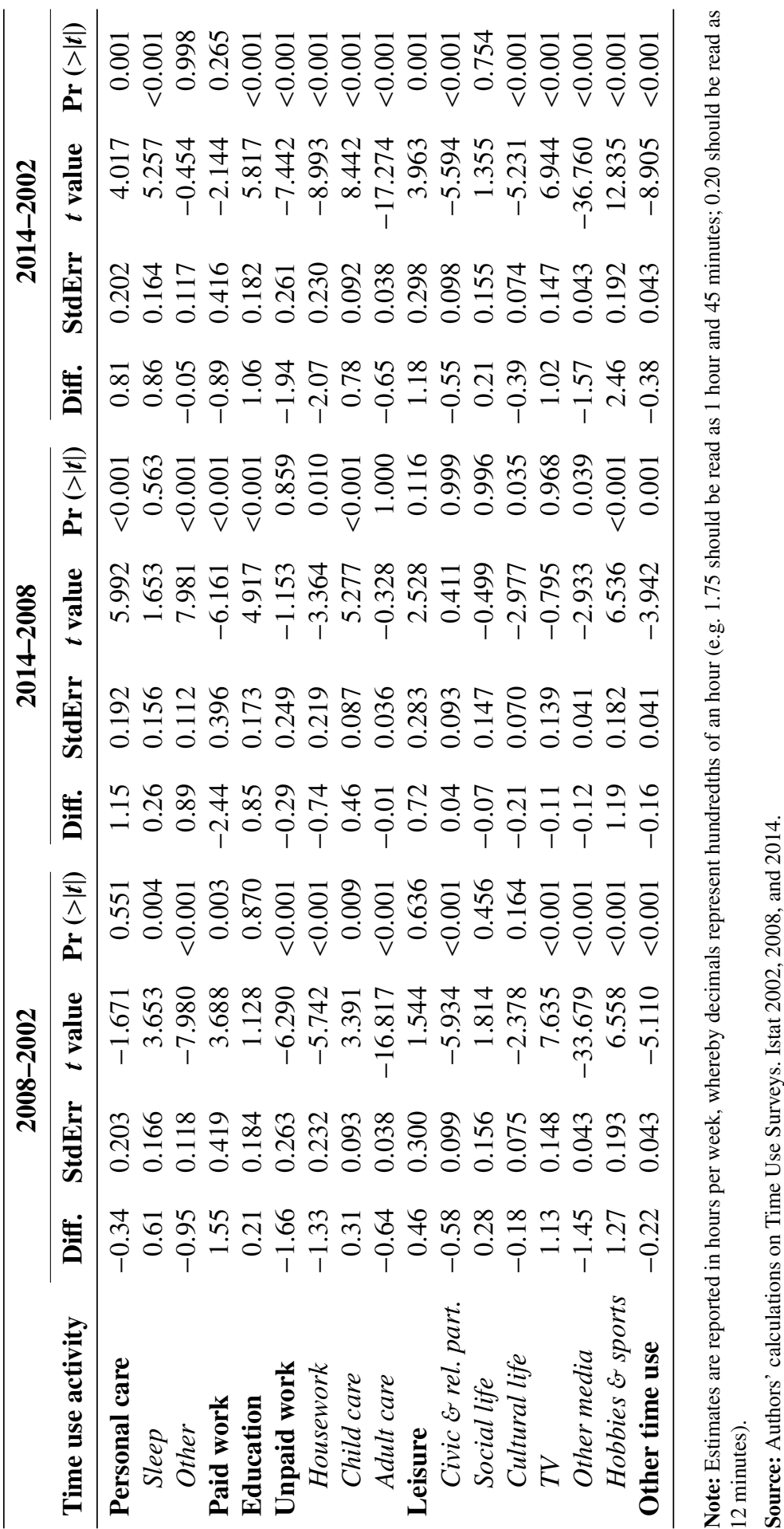
spent on civic participation and using media other than TV. In particular, according to our regression estimates, the time devoted to other mass media (the majority of which is time spent reading the newspaper and listening to the radio) dropped from about $3 \mathrm{~h}$ to less than $1 \mathrm{~h}$ per week for men and from almost $2 \mathrm{~h}$ to $30 \mathrm{~min}$ per week for women. The time spent on cultural life declined by $34 \mathrm{~min}$ for men, and decreased slightly for women $(-11 \mathrm{~min})$, although the change was not statistically significant. Thus, even though the amount of time devoted to leisure was fairly stable between 2002 and 2008, its composition changed considerably. These findings clearly show that to avoid incomplete (or even misleading) interpretations of time use behaviours, it is important to look at the detailed composition of time use categories, rather than relying on broad classifications.

Women and men displayed different unpaid work patterns. While women reduced the time they spent on family work by $1 \mathrm{~h} 40 \mathrm{~min}$ per week, there was no statistically significant change in the time men devoted to family work.

As expected, a comparison of time use regression estimates for 2008 and 2014 points to the existence of a statistically significant negative effect of the recessionary period on paid work (about $3 \mathrm{~h} 45$ min less for the total population). In line with the mancession hypothesis, the magnitude of this effect was greater for men than for women (respectively, about $5 \mathrm{~h}$ and $2 \mathrm{~h}$ less per week). Indeed, in 2014, paid working hours for women had nearly returned to the pre-crisis level of an average of $17 \mathrm{~h}$ per week. For men, by contrast, paid working hours continued to be far lower in 2014, at an average of $32 \mathrm{~h}$ per week, than the initial level of $36 \mathrm{~h}$ per week. This reduction in time spent on paid work was accompanied by an upward trend in time spent on personal care other than sleep and education for both genders. A statistically significant increase in the time spent on leisure is observed only for men, who devoted considerably more time to hobbies and sports, and slightly more time to religious and civic participation (about $1 \mathrm{~h} 30 \mathrm{~min}$ and $25 \mathrm{~min}$ more per week, respectively). While female time spent on hobbies and sports grew by more than one hour per week during the 2008-2014 period, this was the only category of leisure activities for women in which there was a significant change in the recessionary years. It is worth noting that during the entire period of observation (from 20022014), an upward trend was recorded in the time spent on hobbies and sports, from approximately $11 \mathrm{~h}$ to $14 \mathrm{~h}$ per week for men, and from $8 \mathrm{~h}$ to $11 \mathrm{~h}$ per week for women. Men and women displayed different unpaid work behaviours during the recessionary years, with the time spent on unpaid work increasing by about two hours per week for the former, while showing no statistically significant change for the latter. The positive association between the recessionary period and male levels of unpaid work can be explained by the increase in the time men spent on child care and housework (approximately $30 \mathrm{~min}$ and $1 \mathrm{~h} 20 \mathrm{~min}$ more per week, respectively). The increase in the time women devoted to child care was comparable to that among men, whereas the time women spent on housework decreased in the 2008-2014 period. The results for child care are in line with the findings of previous time use studies, which indicate that the employed mothers of today devote roughly the same number hours to child care as the "golden era housewives" 
(Bianchi and Milkie 2010); and with the literature on intensive parenting (e.g. Craig et al. 2014). Summarising, our results highlight the existence of a downward trend in female housework during the entire study period, with women spending about $2 \mathrm{~h}$ less per week on household chores in 2014 than they did in 2002. However, the magnitude of this decline was greater between 2002 and 2008, when the number of hours women spent on paid work was rising. For men, by contrast, the changes in the amount of time spent on unpaid work were concentrated in the recessionary years, whereas differences in household and family care activities were not statistically significant in years prior to the crisis.

\section{Concluding remarks}

This article draws on micro-data from three different editions of the Italian TUS to study the evolution of the use of time among Italian men and women over the 2002-2014 period, while paying specific attention to changes that occurred in the years before and after the beginning of the Great Recession. Our findings indicate that there was a narrowing of the gender gap in unpaid work during the entire period of observation, with men spending about $2 \mathrm{~h}$ more per week on unpaid family time, and women spending around $2 \mathrm{~h}$ less per week on housework between 2002 and 2014. However, while signs of this gender convergence were already visible for women before the recession, it was not until after the beginning of the crisis and the consequent losses in paid work hours that men started to become more involved in household and family care activities.

For women, we observed an increase of about $1 \mathrm{~h}$ and $30 \mathrm{~min}$ per week devoted to paid work time that was mirrored by a similar decline in the number of hours spent on housework during the pre-recessionary period; whereas for men, we found no significant increase in the number of hours spent on family work between 2002 and 2008. Earlier empirical evidence demonstrated that Italian men spent an average of 18 minutes more per day (about $2 \mathrm{~h}$ per week) on unpaid work in $2002 / 3$ than in 1988/9 (Romano 2008). A positive trend in male unpaid work was found in virtually all of the industrialised countries from the 1970s to the early 2000s (e.g. Gimenez-Nadal and Sevilla 2012). According to Fisher et al. (2007), the amount of unpaid work performed by American men significantly rose between 1965 and 2003; however, this change was concentrated within the first decades of the observation period. Our results corroborate the argument made by the scholars that there was a "no change moment" in the time men spent on family work from the late 20th century until the early 2000s.

As expected, we found that the economic crisis negatively affected the time spent on paid work, with an overall decline of about $4 \mathrm{~h}$ per week, leaving both genders with more time available to devote to personal care. Consistent with the mancession literature, our results showed that the paid work losses were greater for men ( $-5 \mathrm{~h}$ per week) than for women ( $-2 \mathrm{~h} 30 \mathrm{~min}$ per week). Whereas the results of Bettio et al. (2012) suggest that the gender gap in unpaid work widened during 
the economic crisis, we found that men performed more and women performed less family work during this period. Specifically, we found that between 2008 and 2014 , men reallocated some of their foregone market work hours to housework $(+1 \mathrm{~h}$ $20 \mathrm{~min}$ ) and to child care $(+32 \mathrm{~min})$, which led to an overall increase of about $2 \mathrm{~h}$ per week spent on unpaid work; while the time women spent on housework declined by an average of 44 minutes per week. However, our finding that the reduction in the number of hours women devoted to family time during the recessionary years was smaller in magnitude than it was in the previous period suggests that the more relevant decrease in the number of hours women were spending on unpaid work took place before the onset of the Great Recession.

\section{Acknowledgements}

This study was carried out as part of the "Age Well Accounts" research project funded by the Joint Programming Initiative "More Years, Better Lives - The Potential and Challenges of Demographic Change".

\section{References}

Aguiar, M. and E. Hurst 2007. Measuring trends in leisure: The allocation of time over five decades. Quarterly Journal of Economics 115: 969-1006.

Aguiar, M., E. Hurst and L. Karabarbounis 2014. Time use during recessions. American Economic Review 103(5): 1664-1696.

Bettio, F., M. Corsi, C. D'Ippoliti, A. Lyberaki, M. S. Lodovici and A. Verashchagina 2012. The impact of the economic crisis on the situation of women and men and on gender equality policies. Synthesis report. Luxembourg: Publications Office of the European Union.

Bianchi, S. M. and M. A. Milkie 2010. Work and family research in the first decade of the 21st century. Journal of Marriage and Family 72(3): 705-725.

Bloemen, H., S. Pasqua and E. Stancanelli 2010. An empirical analysis of the time allocation of Italian couples: Are Italian men irresponsive? Review of Economics of the Household 8(3): 345-369.

Craig, L., A. Powell and C. Smyth 2014. Towards intensive parenting? Changes in the composition and determinants of mothers' and fathers' time with children 1992-2006. The British Journal of Sociology 65(3): 555-579.

Eydoux, A., A. Math and H. Périvier 2014. European labour markets in times of crisis. Revue de l'OFCE (2): 7-14.

Eurostat 2009. Harmonised European time use surveys. Luxemburg: Publications Office of the European Union.

Finegan, T. A. and R. A. Margo 1993. Added and discouraged workers in the late 1930s: A re-examination. NBER Historical Working Paper No. 45. National Bureau of Economic Research. 
Fisher, K., M. Egerton, J. I. Gershuny and J. P. Robinson 2007. Gender convergence in the American heritage time use study (AHTUS). Social Indicators Research 82(1): 1-33.

Folbre, N. 2011. Time, money and unemployment. The New York Times: Economix, August 29th, 2011. Available at: http://economix.blogs.nytimes.com/2011/08/29/ time-money-and-unemployment.

Gimenez-Nadal, J. I. and A. Sevilla 2012. Trends in time allocation: A cross-country analysis. European Economic Review 56(6): 1338-1359.

Hofferth, S. and F. Goldscheider 2010. Does change in young men's employment influence fathering? Family Relations 59: 479-493.

Karamessini, M. and J. Rubery (eds) 2014. Women and austerity: The economic crisis and the future for gender equality. UK: Routledge.

Lahart, J. and E. Zhao 2010. What would you do with an extra hour? Wall Street Journal June 23.

Menniti, A., P. Demurtas, A. De Rose and S. Arima 2015. Housework and child care in Italy: A persistent case of gender inequality. Genus 71(1): 79-108.

Périvier, H. 2014. Men and women during the economic crisis. Employment trends in eight European countries. Revue de l'OFCE (2): 41-84.

Reid, M. 1934. Economics of household production. New York: John Wiley.

Romano, M. C. 2008. Time use in daily life. A multidisciplinary approach to the Time use's analysis. Tech. Rep. ISTAT No 35.

Rubery, J. (ed.) 1988. Women and Recession. London, New York: Routledge and Kegal Paul. Sierminska, E. and Takhtamanova, Y. 2011. Job flows, demographics, and the great recession. In: Who loses in the downturn? Economic crisis, employment and income distribution, 115-154. Emerald Group Publishing Limited.

Zannella, M., B. Hammer, A. Prskawetz and J. Sambt 2018. A quantitative assessment of the rush hour of life in Austria, Italy and Slovenia. European Journal of Population 1-26. 


\section{Appendix}

Table A.1:

Number of time use diaries by year and month

\begin{tabular}{lrcc}
\hline Month/Year & $\boldsymbol{N}$ & Frequency $(\boldsymbol{\%})$ & Cumulative frequency $(\boldsymbol{\%})$ \\
\hline $\mathbf{2 0 0 2 / 3}$ & & & \\
$04 / 2002-06 / 2002$ & 11,997 & 24.3 & 24.3 \\
$07 / 2002-09 / 2002$ & 13,071 & 26.5 & 50.7 \\
$10 / 2002-12 / 2002$ & 12,149 & 24.6 & 75.3 \\
$01 / 2003-03 / 2003$ & 12,184 & 24.7 & 100.0 \\
Total & $\mathbf{4 9 , 4 0 1}$ & $\mathbf{1 0 0 . 0}$ & \\
$\mathbf{2 0 0 8} / \mathbf{9}$ & & & \\
$02 / 2008-04 / 2008$ & 10,652 & 26.7 & 51.9 \\
$05 / 2008-07 / 2008$ & 10,073 & 25.2 & 77.0 \\
$08 / 2008-10 / 2008$ & 10,022 & 25.1 & 100.0 \\
$11 / 2008-01 / 2009$ & 9,196 & 23.0 & \\
Total & $\mathbf{3 9 , 9 4 3}$ & $\mathbf{1 0 0 . 0}$ & 26.6 \\
$\mathbf{2 0 1 3} / \mathbf{4}$ & & & 52.0 \\
$11 / 2013-01 / 2014$ & 10,745 & 26.6 & 100.0 \\
$02 / 2014-04 / 2014$ & 10,268 & 25.4 & \\
$05 / 2014-07 / 2014$ & 9,743 & 24.1 & \\
$08 / 2014-10 / 2014$ & 9,626 & 23.8 & \\
Total & $\mathbf{4 0 , 3 8 2}$ & $\mathbf{1 0 0 . 0}$ & \\
\hline
\end{tabular}

Source: Authors' calculations based on Time Use Surveys. Istat 2002/3, 2008/9, and 2013/4. 
Table A.2:

Weighted sample estimates of the average of use of time by gender, activity, and survey year

\begin{tabular}{|c|c|c|c|c|c|c|c|c|c|}
\hline \multirow{2}{*}{$\begin{array}{l}\text { Time use } \\
\text { activities }\end{array}$} & \multicolumn{3}{|c|}{ Both genders } & \multicolumn{3}{|c|}{ Men } & \multicolumn{3}{|c|}{ Women } \\
\hline & 2002 & 2008 & 2014 & 2002 & 2008 & 2014 & 2002 & 2008 & 2014 \\
\hline Personal care & 78.57 & 77.87 & 78.73 & 78.81 & 77.95 & 78.71 & 78.32 & 77.78 & 78.74 \\
\hline Sleep & 57.31 & 57.69 & 57.85 & 57.24 & 57.44 & 57.59 & 57.39 & 57.93 & 58.10 \\
\hline Other & 21.25 & 20.18 & 20.88 & 21.57 & 20.51 & 21.12 & 20.93 & 19.85 & 20.64 \\
\hline Paid work & 26.16 & 28.23 & 24.81 & 35.63 & 37.21 & 32.46 & 16.76 & 19.27 & 17.27 \\
\hline Education & 4.33 & 4.34 & 5.05 & 4.18 & 4.16 & 4.98 & 4.48 & 4.52 & 5.11 \\
\hline Unpaid work & 24.15 & 23.07 & 23.47 & 11.02 & 11.10 & 12.50 & 37.19 & 35.00 & 34.29 \\
\hline Housework & 20.27 & 19.74 & 19.82 & 8.60 & 9.16 & 10.25 & 31.86 & 30.29 & 29.27 \\
\hline Child care & 3.06 & 2.97 & 3.31 & 1.81 & 1.62 & 1.95 & 4.30 & 4.32 & 4.65 \\
\hline Adult care & 0.82 & 0.35 & 0.34 & 0.60 & 0.31 & 0.30 & 1.03 & 0.39 & 0.37 \\
\hline Leisure & 34.33 & 34.19 & 35.65 & 37.91 & 37.26 & 39.08 & 30.78 & 31.13 & 32.28 \\
\hline Civic $\mathcal{E}$ rel. part. & 2.19 & 1.82 & 2.05 & 1.66 & 1.37 & 1.78 & 2.73 & 2.27 & 2.31 \\
\hline Social life & 7.68 & 7.86 & 7.86 & 8.50 & 8.67 & 8.61 & 6.87 & 7.06 & 7.11 \\
\hline Cultural life & 2.41 & 2.00 & 1.90 & 2.52 & 1.87 & 1.82 & 2.31 & 2.12 & 1.99 \\
\hline$T V$ & 10.58 & 11.37 & 11.34 & 11.72 & 12.51 & 12.46 & 9.44 & 10.24 & 10.22 \\
\hline Other media & 2.01 & 0.66 & 0.52 & 2.46 & 0.85 & 0.67 & 1.56 & 0.48 & 0.37 \\
\hline Hobbies $\mathcal{E}$ sports & 9.46 & 10.47 & 11.99 & 11.04 & 11.99 & 13.75 & 7.88 & 8.96 & 10.26 \\
\hline Other time use & 0.46 & 0.30 & 0.13 & 0.45 & 0.31 & 0.12 & 0.47 & 0.30 & 0.15 \\
\hline
\end{tabular}

Note: Estimates are reported in hours per week, whereby decimals represent hundredths of an hour (e.g. 1.75 should be read as 1 hour and 45 minutes; 0.20 should be read as 12 minutes). Estimates refer to an average day of the week. Source: Authors' calculations based on Time Use Surveys. Istat 2002/3, 2008/9, and 2013/4. 
Table A.3:

Sample size and Chi Square Independence Test by year and socio-demographic variables

\begin{tabular}{|c|c|c|c|c|c|c|}
\hline & \multicolumn{2}{|c|}{2002} & \multicolumn{2}{|c|}{2008} & \multicolumn{2}{|c|}{2014} \\
\hline & $N$ & $\%$ & $N$ & $\%$ & $N$ & $\%$ \\
\hline \multicolumn{7}{|l|}{ Geographic area } \\
\hline North & 15,218 & 45.7 & 11,121 & 43.3 & 10,890 & 42.5 \\
\hline Centre & 5,985 & 18.0 & 4,451 & 17.3 & 4,607 & 18.0 \\
\hline South & 12,124 & 36.4 & 10,103 & 39.3 & 10,154 & 39.6 \\
\hline Independence test & \multicolumn{2}{|c|}{$\chi^{2}=92.10$} & \multicolumn{2}{|c|}{ d.f. $=4$} & \multicolumn{2}{|c|}{$\mathbf{P}<0.001$} \\
\hline \multicolumn{7}{|l|}{ Age group } \\
\hline $15-24$ & 5,458 & 16.4 & 3,933 & 15.3 & 3,859 & 15.0 \\
\hline $25-34$ & 6,918 & 20.8 & 4,618 & 18.0 & 4,146 & 16.2 \\
\hline $35-44$ & 8,046 & 24.1 & 6,401 & 24.9 & 5,775 & 22.5 \\
\hline $45-54$ & 6,862 & 20.6 & 5,706 & 22.2 & 6,577 & 25.6 \\
\hline $55-64$ & 6,043 & 18.1 & 5,017 & 19.5 & 5,294 & 20.6 \\
\hline Independence test & \multicolumn{2}{|c|}{$\chi^{2}=436.95$} & \multicolumn{2}{|c|}{ d.f. $=8$} & \multicolumn{2}{|c|}{$P<0.001$} \\
\hline \multicolumn{7}{|l|}{ Educational level } \\
\hline High & 2,956 & 8.9 & 3,131 & 12.2 & 4,040 & 15.7 \\
\hline Medium & 13,100 & 39.3 & 10,371 & 40.4 & 10,894 & 42.5 \\
\hline Low & 17,271 & 51.8 & 12,173 & 47.4 & 10,717 & 41.8 \\
\hline Independence test & \multicolumn{2}{|c|}{$\chi^{2}=919.44$} & \multicolumn{2}{|c|}{ d.f. $=4$} & \multicolumn{2}{|c|}{$\mathrm{P}<0.001$} \\
\hline \multicolumn{7}{|l|}{ Couple } \\
\hline Yes & 19,734 & 59.2 & 13,943 & 54.3 & 12,714 & 49.6 \\
\hline Not & 13,593 & 40.8 & 11,732 & 45.7 & 12,937 & 50.4 \\
\hline Independence test & \multicolumn{2}{|c|}{$\chi^{2}=\mathbf{5 4 8 . 3 6}$} & \multicolumn{2}{|c|}{ d.f. $=2$} & \multicolumn{2}{|c|}{$\mathbf{P}<0.001$} \\
\hline \multicolumn{7}{|l|}{ Child } \\
\hline Yes & 11,269 & 33.8 & 8,286 & 32.3 & 8,118 & 31.6 \\
\hline Not & 22,058 & 66.2 & 17,389 & 67.7 & 17,533 & 68.4 \\
\hline Independence test & \multicolumn{2}{|c|}{$\chi^{2}=33.81$} & \multicolumn{2}{|c|}{ d.f. $=2$} & \multicolumn{2}{|c|}{$\mathrm{P}<0.001$} \\
\hline
\end{tabular}

Source: Authors' calculations based on time use surveys. Istat 2002/3, 2008/9, and 2013/4. 
Table A.4:

Regression estimates of the average use of time by activity and survey year - Both genders

\begin{tabular}{|c|c|c|c|c|c|c|}
\hline \multirow[b]{2}{*}{ Time use activities } & \multicolumn{2}{|c|}{2002} & \multicolumn{2}{|c|}{2008} & \multicolumn{2}{|c|}{2014} \\
\hline & Mean & StdErr & Mean & StdErr & Mean & StdErr \\
\hline Personal care & 78.01 & 0.124 & 77.46 & 0.111 & 78.50 & 0.107 \\
\hline Sleep & 57.16 & 0.101 & 57.56 & 0.091 & 57.79 & 0.087 \\
\hline Other & 20.85 & 0.072 & 19.90 & 0.065 & 20.70 & 0.062 \\
\hline Paid work & 26.98 & 0.256 & 28.20 & 0.230 & 24.43 & 0.221 \\
\hline Education & 5.55 & 0.112 & 5.75 & 0.100 & 6.69 & 0.097 \\
\hline Unpaid work & 22.92 & 0.161 & 22.34 & 0.144 & 23.13 & 0.139 \\
\hline Housework & 18.12 & 0.142 & 17.73 & 0.127 & 18.04 & 0.122 \\
\hline Child care & 4.01 & 0.057 & 4.29 & 0.051 & 4.79 & 0.049 \\
\hline Adult care & 0.79 & 0.023 & 0.31 & 0.021 & 0.30 & 0.020 \\
\hline Leisure & 34.01 & 0.183 & 33.92 & 0.164 & 34.94 & 0.158 \\
\hline Civic $\mathcal{E}$ rel. part. & 2.13 & 0.060 & 1.62 & 0.054 & 1.85 & 0.052 \\
\hline Social life & 7.48 & 0.095 & 7.72 & 0.085 & 7.56 & 0.082 \\
\hline Cultural life & 2.61 & 0.046 & 2.23 & 0.041 & 2.07 & 0.039 \\
\hline$T V$ & 9.78 & 0.090 & 10.85 & 0.081 & 10.72 & 0.078 \\
\hline Other media & 2.38 & 0.026 & 0.68 & 0.024 & 0.52 & 0.023 \\
\hline Hobbies and sports & 9.63 & 0.118 & 10.83 & 0.106 & 12.22 & 0.102 \\
\hline Other time use & 0.54 & 0.026 & 0.33 & 0.024 & 0.15 & 0.023 \\
\hline
\end{tabular}

Note: Estimates are reported in hours per week, whereby decimals represent hundredths of an hour (e.g. 1.75 should be read as 1 hour and 45 minutes; 0.20 should be read as 12 minutes). Estimates refer to an average day of the week. Source: Authors' calculations based on time use surveys. Istat 2002/3, 2008/9, and 2013/4. 
Table A.5:

Regression estimates of the average use of time by activity and survey year - Men

\begin{tabular}{|c|c|c|c|c|c|c|}
\hline \multirow[b]{2}{*}{ Time use activities } & \multicolumn{2}{|c|}{2002} & \multicolumn{2}{|c|}{2008} & \multicolumn{2}{|c|}{2014} \\
\hline & Mean & StdErr & Mean & StdErr & Mean & StdErr \\
\hline Personal care & 78.22 & 0.149 & 77.47 & 0.140 & 78.39 & 0.139 \\
\hline Sleep & 57.06 & 0.122 & 57.26 & 0.114 & 57.48 & 0.114 \\
\hline Other & 21.16 & 0.087 & 20.21 & 0.082 & 20.92 & 0.081 \\
\hline Paid work & 36.37 & 0.308 & 37.25 & 0.290 & 32.15 & 0.287 \\
\hline Education & 5.27 & 0.135 & 5.47 & 0.127 & 6.49 & 0.126 \\
\hline Unpaid work & 10.13 & 0.194 & 10.63 & 0.182 & 12.50 & 0.181 \\
\hline House work & 6.74 & 0.170 & 7.29 & 0.160 & 8.64 & 0.159 \\
\hline Child care & 2.81 & 0.068 & 3.06 & 0.064 & 3.59 & 0.063 \\
\hline Adult care & 0.59 & 0.028 & 0.27 & 0.026 & 0.27 & 0.026 \\
\hline Leisure & 37.48 & 0.220 & 36.85 & 0.207 & 38.17 & 0.206 \\
\hline Civic participation & 1.61 & 0.072 & 1.16 & 0.068 & 1.58 & 0.068 \\
\hline Social life & 8.24 & 0.115 & 8.43 & 0.108 & 8.19 & 0.107 \\
\hline Cultural life & 2.68 & 0.055 & 2.11 & 0.052 & 1.99 & 0.051 \\
\hline$T V$ & 10.96 & 0.109 & 11.96 & 0.102 & 11.82 & 0.101 \\
\hline Other media & 2.82 & 0.032 & 0.87 & 0.030 & 0.68 & 0.030 \\
\hline Hobbies and sports & 11.18 & 0.142 & 12.31 & 0.133 & 13.90 & 0.132 \\
\hline Other time use & 0.53 & 0.032 & 0.33 & 0.030 & 0.13 & 0.030 \\
\hline
\end{tabular}

Note: Estimates are reported in hours per week, whereby decimals represent hundredths of an hour (e.g. 1.75 should be read as 1 hour and 45 minutes; 0.20 should be read as 12 minutes). Estimates refer to an average day of the week. Source: Authors' calculations based on Time Use Surveys. Istat 2002/3, 2008/9, and 2013/4. 
Table A.6:

Regression estimates of the average use of time by activity and survey year - Women

\begin{tabular}{|c|c|c|c|c|c|c|}
\hline \multirow[b]{2}{*}{ Time use activities } & \multicolumn{2}{|c|}{2002} & \multicolumn{2}{|c|}{2008} & \multicolumn{2}{|c|}{2014} \\
\hline & Mean & StdErr & Mean & StdErr & Mean & StdErr \\
\hline Personal care & 77.79 & 0.150 & 77.45 & 0.137 & 78.60 & 0.134 \\
\hline Sleep & 57.25 & 0.122 & 57.86 & 0.112 & 58.11 & 0.109 \\
\hline Other personal & 20.54 & 0.088 & 19.59 & 0.080 & 20.48 & 0.078 \\
\hline Paid work & 17.59 & 0.310 & 19.14 & 0.283 & 16.70 & 0.277 \\
\hline Education & 5.83 & 0.136 & 6.04 & 0.124 & 6.89 & 0.121 \\
\hline Unpaid work & 35.71 & 0.195 & 34.05 & 0.177 & 33.76 & 0.174 \\
\hline Housework & 29.50 & 0.171 & 28.17 & 0.156 & 27.43 & 0.153 \\
\hline Child care & 5.21 & 0.068 & 5.53 & 0.062 & 5.99 & 0.061 \\
\hline Adult care & 0.99 & 0.028 & 0.35 & 0.026 & 0.34 & 0.025 \\
\hline Leisure & 30.53 & 0.222 & 31.00 & 0.202 & 31.71 & 0.198 \\
\hline Civic $\mathcal{E}$ rel. part. & 2.66 & 0.073 & 2.07 & 0.066 & 2.11 & 0.065 \\
\hline Social life & 6.73 & 0.115 & 7.01 & 0.105 & 6.94 & 0.103 \\
\hline Cultural life & 2.53 & 0.055 & 2.35 & 0.050 & 2.14 & 0.049 \\
\hline$T V$ & 8.61 & 0.109 & 9.74 & 0.100 & 9.63 & 0.098 \\
\hline Other media & 1.93 & 0.032 & 0.48 & 0.029 & 0.36 & 0.028 \\
\hline Hobbies and sports & 8.08 & 0.143 & 9.34 & 0.125 & 10.53 & 0.122 \\
\hline Other time use & 0.54 & 0.032 & 0.32 & 0.029 & 0.16 & 0.029 \\
\hline
\end{tabular}

Note: Estimates are reported in hours per week, whereby decimals represent hundredths of an hour (e.g. 1.75 should be read as 1 hour and 45 minutes; 0.20 should be read as 12 minutes). Estimates refer to an average day of the week. Source: Authors' calculations based on Time Use Surveys. Istat 2002/3, 2008/9, and 2013/4. 